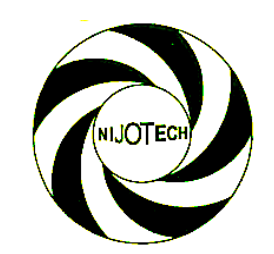

Nigerian Journal of Technology (NIJOTECH)

Vol. 38, No. 4, October 2019, pp. 965 - 973

Copyright@ Faculty of Engineering, University of Nigeria, Nsukka,

Print ISSN: 0331-8443, Electronic ISSN: 2467-8821

www.nijotech.com

http://dx.doi.org/10.4314/njt.v38i4.20

\title{
EVALUATION OF SOME PROCESS PARAMETERS FOR PRODUCTION OF INVESTMENT BAR CASTINGS
}

\author{
S. O. Areo ${ }^{1, *}$, R. H. Khan ${ }^{2}$, M. B. Ndaliman ${ }^{3}$ and S. A. Lawal ${ }^{4}$ \\ $\mathbf{1 , 2 , 3 , 4}$, Dept. of MeChanical EngineERING, Fed. Univ. OF TeChnology, MinNA, Niger StATE, NigERIA \\ E-mail addresses: 1 areostephen@gmail.com, ${ }^{2}$ reyazkhan1@yahoo.com, \\ 3 mbndaliman@yahoo.com 4 lawalsunday@futminna.edu.ng
}

\begin{abstract}
This investigation aims at evaluating some process parameters for the production of aluminium alloy investment castings using polystyrene as pattern material and Plaster of Paris as investment slurry. The process parameters considered are the shell thickness, casting thickness and pouring temperature and the effect of varying these parameters on the mechanical properties of aluminium silicon magnesium alloy (A356) produced through the investment casting method is being investigated in this work. The effects of these variables were studied using design of experiments (D.O.E) via Taguchi's Lg orthogonal array method. The castings produced were subjected to mechanical tests such as tensile strength, impact strength and hardness test using Monsanto tensometer and Avery impact and Avery hardness testing machines respectively. The results obtained were analysed using Minitab software 17. The results showed that the tensile strength, impact strength and hardness were optimum when the shell thickness was 5 mm, pouring temperature was $665^{\circ} \mathrm{C}$ and the bar cross section was $64 \mathrm{~mm}^{2}$ respectively. The investigation concludes that investment shell of thin thickness, casting thickness of smaller bar sections and lower pouring temperatures in the range of $665^{\circ} \mathrm{C}-690^{\circ} \mathrm{C}$ were the most suitable parameters that produced optimum results with better mechanical properties in this study.
\end{abstract}

Keywords: Investment casting, Polystyrene pattern, Plaster of Paris slurry.

\section{INTRODUCTION}

Investment casting is one of the metal casting processes in which a wax or polystyrene pattern is coated with a refractory ceramic slurry, as the ceramic material hardens; the internal geometry takes the shape of the casting. The hardened ceramic material with the embedded pattern is heated in an oven, this causes the pattern to burn off and a cavity called shell is left behind, which is then filled with a molten metal and as the metal solidifies in the shell, it becomes an exact replica of the original pattern, the shell is then broken and the casting is removed. The advantages of this process are numerous; it produces very good dimensional accuracy and very fine finishing and is best used for producing intricate and very difficult to machine parts that are difficult to produce by some other means. This work emphasises on the effect of process parameters: shell thickness, casting thickness and pouring temperature on mechanical properties of investment castings. The shell thicknesses used are $5 \mathrm{~mm}, 7 \mathrm{~mm}$ and $9 \mathrm{~mm}$, while the bar cross sections used are $64 \mathrm{~mm}^{2}, 100$ $\mathrm{mm}^{2}$ and $144 \mathrm{~mm}^{2}$ and the pouring temperatures considered were $665^{\circ} \mathrm{C}, 690^{\circ} \mathrm{C}$ and $715^{\circ} \mathrm{C}$. The choice of the $5 \mathrm{~mm}$ shell thickness was arrived at, after other shells with lower thickness produced by the researchers were unable to withstand the pressures exerted on its walls during the metal pouring which led to the collapse of the shells, and it was observed that additional thickness above $9 \mathrm{~mm}$ was a waste of material since $9 \mathrm{~mm}$ thickness had enough strength to withstand the pressures exerted on the walls during metal pouring. The bar cross sections were chosen to suit the standard that could be easily managed on the machines used to carry out the mechanical tests. The liquidus temperature of the

\footnotetext{
* Corresponding author, tel: +234-803-586-6770
} 
Aluminium alloy used is $615^{\circ} \mathrm{C}$ Wu et al, [1] and Legoretta et al, [2]. Pouring were carried out at $665^{\circ} \mathrm{C}, 690^{\circ} \mathrm{C}$, and $715^{\circ} \mathrm{C}$ by adding Superheat of $50^{\circ} \mathrm{C}, 75^{\circ} \mathrm{C}$ and $100^{\circ} \mathrm{C}$ to the liquidus temperature to ensure that the molten alloy does not chill out (solidify) before the cavity is completely filled during pouring. In casting, knowing the optimum casting parameters of the shell thickness, casting thickness and pouring temperature will enable the foundry man to produce the best cast.

Nikhil and Karunakar [3], carried out a research work on the 'effect of process parameters on the mechanical properties of investment castings produced by using expendable polystyrene pattern. The investigation was carried out to determine the mechanical properties of aluminium alloy A713 produced through investment casting. The castings were produced under the following process parameters; firing temperature, pouring temperature, firing time and mixing of silica sand of different grain fineness numbers to investigate their effects on the tensile strength, impact strength and hardness. From their study, it was deduced that high mould firing temperature, higher pouring temperature, maximum firing time and high grain fineness number significantly reduced the mechanical properties of $\mathrm{A} 713$ alloy castings produced by the investment casting process. Their work did not show how shell thickness or casting thickness affect the mechanical properties.

Phuan [4], carried out an evaluation of thermal property of mould wall material for investment casting and the effect of layers on the hardness of the casting produced. The work investigated and established a correlation between the mould wall thickness and the mechanical properties of the nonferrous alloy in investment casting. Mould material of the fine stucco system was investigated. The investigation proposed four moulds with different thicknesses of $5,7,9$, and 11 layers. The pouring temperature was set at $660^{\circ} \mathrm{C}$. After the pouring, the temperatures of the outer and inner wall of the mould materials were recorded until the temperature reach the steady state condition. Finite element analysis based on a plane strain assumption was employed to evaluate the thermal conductivity $k$, of the mould material with different thicknesses, based on the experimental steady state temperature of the inner and outer surface of the mould material. The mechanical properties of the casting materials were investigated by observing the microstructure and performing Vickers Hardness Test on the casting specimens. In the findings, the thermal conductivity $k$ values of the mould materials were almost the same. The percentage of the silicon flakes for the cast produced decreased with the increased in the mould wall thickness. The Vickers Hardness also decreased with the increased in the mould wall thickness. One area of interest in his work was the similarity in the wall thickness of the mould used which is comparable to the shell thickness used as one of the process parameters in this work. His interest in evaluating the thermal conductivity of the mould material with different thicknesses differ from the other process parameters and area of investigation used in this work.

Shrikant et al [5] studied the effect of section thickness on micro-structure of grey cast iron, though their investigation was done using cast iron, but the area of interest in their work which is related to this work is the effect the different section thickness has on the mechanical properties. The work was done using a stepped bar with varying thicknesses of 3, 6, 10 and $16 \mathrm{~mm}$. It was observed in their work that the microstructures of thinner sections are fine compared to thicker sections which was due to the difference in cooling rate, since cooling rate of thin section is higher than the thick section of the stepped bar. Hardness of the different sections was taken using procast machine. They concluded from their findings, that hardness was higher in thin sections than in thicker sections. Their work is related to the varying bar thickness used in this work. Similar to the work carried out by Shrikant et al, Sigworth [6] carried out some work on the quality of aluminium castings using a standard mould of ASTM B108 and Aluminium Association (AA) mould to cast a testbar of aluminium alloy A356 which had varying thicknesses of 10,12 , 22,36 and $50(\mathrm{~mm})$. From his work he was able to show that better degassing practice results in significant improvement in casting quality and iron is detrimental to quality. He proposed a quality index and equations which can give mechanical properties as a function of defect concentration. Tensile test samples were taken from the five sections of the testbar; each having a different solidification rate and section thickness. The results of the test he carried out on the testbar with varying thickness is shown in Table 1.

From Table 1 it was observed that as the section thickness increases, the time for solidification also increases but the ultimate tensile strength decreases. 
The dendritic arm spacing (DAS) can also be used to estimate the local solidification time. The study expressed the fact that degassing, filtration, grain refinement and modification have influence on the mechanical properties and porosity is the most serious problem in casting, the amount of porosity in the casting depends on factors like- Solidification rate, gas content, metal cleanliness, pressure in casting, modification and grain refinement. The areas of similarities in the work and the present study is in the varying section thickness, however, his work did not discuss about varying the pouring temperature or varying the mould size or shell thickness. The gap this research work seeks to fill is the evaluation of the effects of shell thickness, casting thickness and pouring temperature on the tensile strength, impact strength and hardness properties of Aluminium Silicon Magnesium (A356) alloy.

\section{MATERIALS AND METHODS}

\subsection{Materials}

The following materials were used: Polystyrene pattern material which has a density value of $2 \mathrm{~g} / \mathrm{cm}^{3}$, top gum glue for bonding the pattern materials at the joints of the sprue, sprue base well, runner, ingate, projections or risers, investment slurry material of plaster of Paris powder which has a fineness number of $-100 \mu \mathrm{m}$ with silica sand of $-75 \mu \mathrm{m}$, the casting material used is Aluminium Silicon Magnesium (A356) alloy with the elemental composition shown in Table 2, which was determined by sparkling method using spectrometer.

\subsection{Methods}

\subsubsection{Investment casting}

The basic processes involved in investment casting are shown in Figure 1.

Polystyrene pattern of bar with different cross sections of $64 \mathrm{~mm}^{2}, 100 \mathrm{~mm}^{2}$ and $144 \mathrm{~mm}^{2}$ were cut out using hacksaw and blades. The surfaces were smoothened using smooth emerald paper with grit number P220. The sprue, sprue well, runner/ingate and projections were assembled together with a top gum glue to form an assembly shown in Fig. 2. The dimensions of the gating elements are as shown in Table 3.

Table 1: Average Tensile properties of A356 alloy in AA mould

\begin{tabular}{ccccc}
\hline S/N & Thickness $(\mathrm{mm})$ & UTS $\left(\mathrm{N} / \mathrm{mm}^{2}\right)$ & Dendritic Arm Spacing (Microns) & Solidification Time (sec) \\
\hline 1 & 10 & 288 & 33 & 11 \\
2 & 12 & 284 & 25 & 25 \\
3 & 22 & 274 & 38 & 36 \\
4 & 36 & 252 & 46 & 63 \\
5 & 50 & 246 & 51 & 100 \\
\hline
\end{tabular}

Table 2: Elemental composition of the Al -alloy

\begin{tabular}{ccccccccc}
\hline Element & $\mathrm{Al}$ & $\mathrm{Si}$ & $\mathrm{Mg}$ & $\mathrm{Cu}$ & $\mathrm{Fe}$ & $\mathrm{Ti}$ & $\mathrm{Mn}$ & $\mathrm{Zn}$ \\
\hline$\%$ & 91.38 & 7.5 & 0.39 & 0.20 & 0.20 & 0.13 & 0.10 & 0.10 \\
\hline
\end{tabular}

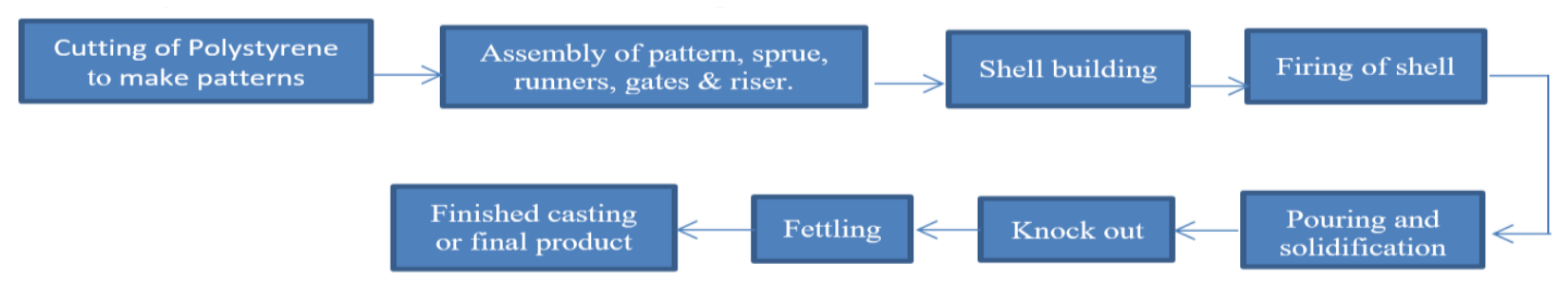

Figure 1: Flow chart of the casting process

Table 3: Dimensions of the gating elements for the bar.

\begin{tabular}{lccc}
\hline Part & Thickness/ height $(\mathrm{mm})$ & Length $(\mathrm{mm})$ & Width $(\mathrm{mm})$ \\
\hline & & Entry & Exit \\
Sprue & 50 & 19.14 & 12.23 \\
Sprue well & 30.66 & & \\
Runner & & 15.33 & 15.33 \\
Ingates & 8 & 15.33 & 15.33 \\
& 10 & 15.33 & 15.33 \\
& 12 & 15.33 & 15.33 \\
\hline
\end{tabular}


The next step is the Shell building which was done by placing the assembled pattern and gating system in an open strawboard box that was prepared for the purpose of temporarily housing the assembled pattern, gating system and the slurry before the slurry sets to become a shell for the assembled pattern and gating system. Pins were used to position the pattern and gating system in the strawboard box. The positioning of the pattern and gating system was carried out to create a gap between the pattern/gating system and the strawboard box to reflect the thickness of the desired shell. The varying thickness of the shell formed were $5 \mathrm{~mm}, 7 \mathrm{~mm}$ and $9 \mathrm{~mm}$ for each set of bars.

The investment slurry material which comprised of the plaster of Paris and silica sand were mixed in the ratio of 3:2 that is; the composition of the investment slurry material was $60 \%$ of plaster of Paris by weight while the silica sand was $40 \%$ by weight. This mixture was manually mixed by hand until it became a homogeneous mixture of powder. The homogeneous mixture of powder was then weighed and mixed with equivalent weight of water in the ratio of $1: 1$ as shown in Table 4. This composition was arrived at, after several trials of varying the mix ratio of the plaster of Paris, silica sand and water to produce investment shells. These mixed values in Table 4 produced better shells that were used for the casting.

Table 4: Investment slurry material mix for bars.

\begin{tabular}{llll}
\hline $\begin{array}{l}\text { Test } \\
\text { casting }\end{array}$ & $\begin{array}{l}\text { P.o.P } \\
(\%)\end{array}$ & $\begin{array}{l}\text { Silica Sand } \\
(\%)\end{array}$ & $\begin{array}{l}\text { Water } \\
(\%)\end{array}$ \\
\hline Bar & 30 & 20 & 50 \\
\hline
\end{tabular}

The investment slurry material was mixed with water to form slurry. The mixing was done using Kenwood professional mixer with model number PM 900 which enabled the breaking of the globules into smaller form and also ensured the uniformity in the conglomerates of the slurry. This slurry was then poured into the strawboard box housing the pattern assembly. It was poured up to the marked level on the strawboard indicating the required thickness. The slurry was then allowed to set. The setting time was between 4 to 5 minutes. After the setting, the strawboard was removed and the shell formed was allowed to dry at room temperature of between $20^{\circ} \mathrm{C}$ to $25^{\circ} \mathrm{C}$ for a period of 5 days. Fig. 3 shows the strawboard box temporarily housing the assembled pattern and the poured slurry and Fig. 4 shows the bar shells that were formed, when the shells had set and were left for drying. Burning of polystyrene pattern and firing of shells was achieved by heating it in an oven for a period of 4 hours at an average temperature of $250^{\circ} \mathrm{C}$. Longer time was spent in attaining the desired burning of the polystyrene because of the capacity of the oven that was available.

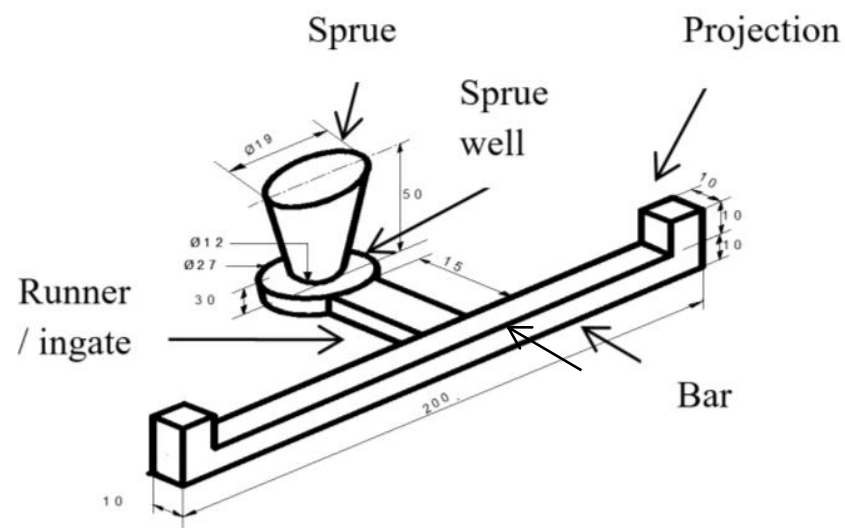

Fig. 2: Assembly of pattern with the gating system for $10 \mathrm{~mm}$ square bar cross section

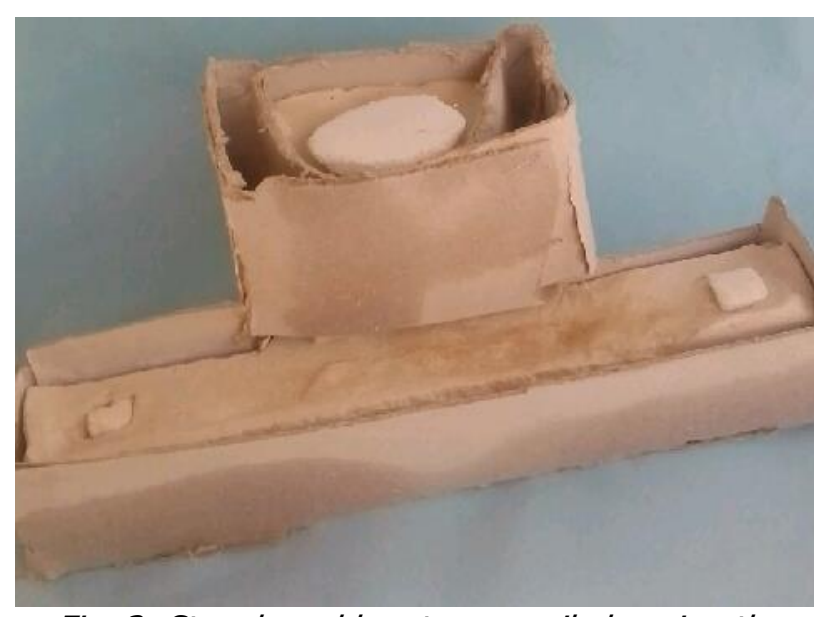

Fig. 3: Strawboard box temporarily housing the pattern and the poured s/urry

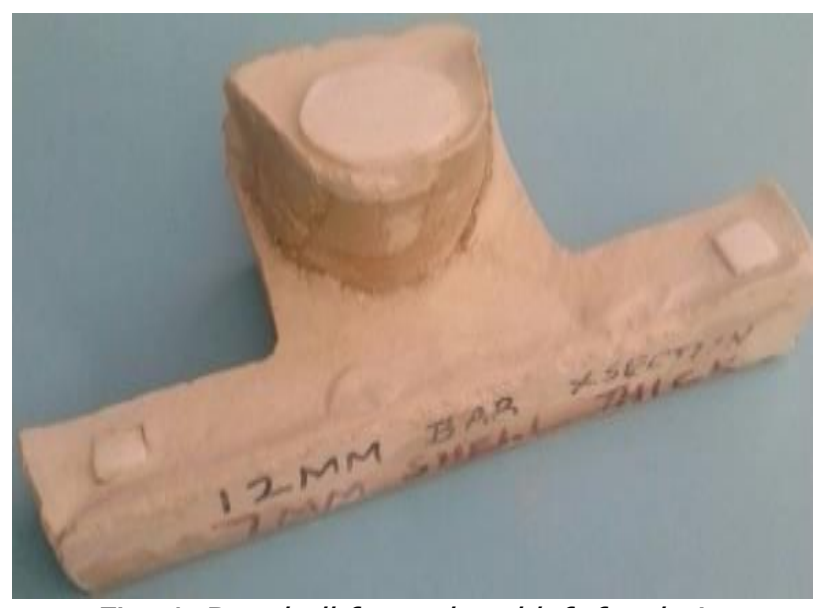

Fig. 4: Bar shell formed and left for drying 
The maximum temperature that was obtainable by the oven was $250^{\circ} \mathrm{C}$. The importance of the burning and firing of the shell is to ensure that all the polystyrene used for making the pattern and the gating system are completely vaporized and to strengthen the shells in preparation for receiving the aluminium melt. Fig. 5 shows the shells produced after the burning of the polystyrene and firing of the shells for the bar.

The charge preparation, melting and pouring of molten aluminium alloy was done by using aluminium alloy A356. Gas crucible furnace was used to melt the aluminium alloy while the liquidus temperature of the alloy used was $615^{\circ} \mathrm{C}$ [1][2]. The pouring temperature used for the castings from the process parameters were $665^{\circ} \mathrm{C}, 690^{\circ} \mathrm{C}$ and $715^{\circ} \mathrm{C}$ for each run of the experiment using $665^{\circ} \mathrm{C}$ as the lower limit and $715^{\circ} \mathrm{C}$ as the upper limit of pouring. The temperatures were measured using digital Fluke mini $\mathrm{K}$ thermocouple immersion pyrometer. It is a thermocouple made from base metal (Chromel-Alumel), used for general purpose and can measure temperatures within the range of $0^{\circ} \mathrm{C}$ and $1100^{\circ} \mathrm{C}$. A clean and preheated plunging tool was also used to slowly plunge $100 \mathrm{~g}$ of Degasser 185 (Chlorine) tablet to the bottom of the melt when the temperature was approaching $650^{\circ} \mathrm{C}$. This degassing was done to eliminate the hydrogen gas in the melt and to improve its castability. The flux used during this process was produced by mixing of $40 \%$ of potassium chloride with $60 \%$ of sodium chloride $(\mathrm{KCl}$ and $\mathrm{NaCl})$. One percent of this flux mixture $(150 \mathrm{~g})$ was used on a $15 \mathrm{~kg}$ weight of melt. The dross obtained was carefully removed, and a clean melt was poured into the prepared shell.

After the solidification of the test castings in the investment shells, the shells were broken with a wooden mallet to remove the casting. Fig. 6 shows the bar castings after the knockout operation for a $10 \mathrm{~mm}$ cross section bar produced in a $9 \mathrm{~mm}$ thickness shell at the pouring temperature of $665^{\circ} \mathrm{C}$.

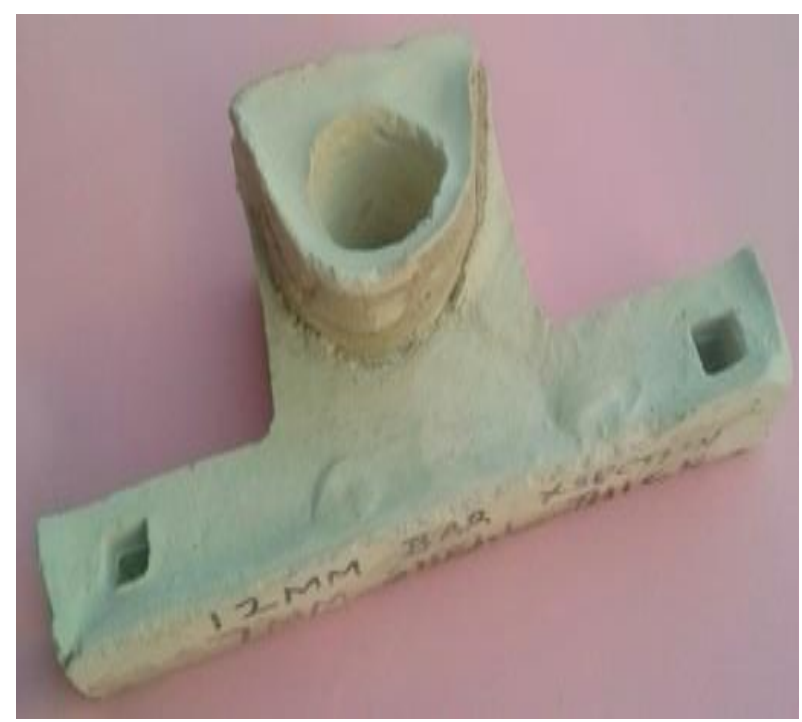

Fig 5: Shell produced after burning of polystyrene and firing

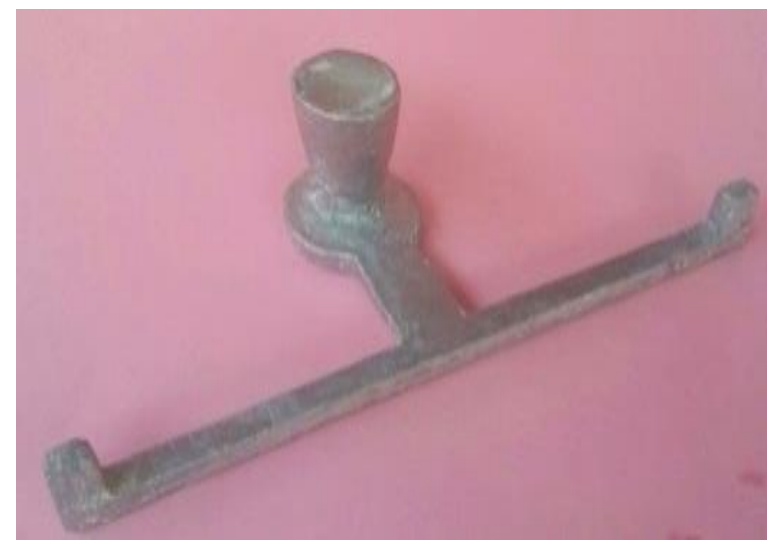

Fig. 6: Bar casting after knockout and cleaning operation

This experimental procedure was used to produce square bars of $64 \mathrm{~mm}^{2}, 100 \mathrm{~mm}^{2}$, and $144 \mathrm{~mm}^{2}$ cross sections using the factor levels of process parameters shown in Table 5. Also, the Taguchi $\mathbf{L g}\left(\mathbf{3}^{3}\right)$ experimental design layout obtained using Minitab 17 software is shown in Table 6.

Table 5: Process parameters with levels of treatment.

\begin{tabular}{cccccc}
\hline $\mathrm{S} / \mathrm{n}$ & Process Parameters & Unit. & \multicolumn{3}{c}{ Level } \\
\cline { 4 - 6 } & & & 1 & 2 & 3 \\
\hline 1 & Shell thickness & $\mathrm{mm}$ & 5 & 7 & 9 \\
2 & Pouring temperature & ${ }^{\circ} \mathrm{C}$ & 665 & 690 & 715 \\
3 & Bar cross section & $\mathrm{mm}^{2}$ & 64 & 100 & 144 \\
\hline
\end{tabular}


Table 6: Taguchi's $L g\left(3^{3}\right)$ experimental layout obtained using Minitab 17 software.

\begin{tabular}{c|ccc}
\hline \multirow{2}{*}{ Runs of experiments } & \multicolumn{3}{|c}{ Process parameters for bar } \\
\cline { 2 - 4 } & $\begin{array}{c}\text { Shell thickness }(\mathrm{mm}) \\
(\mathrm{A})\end{array}$ & $\begin{array}{c}\text { Pouring Temperature }\left({ }^{\circ} \mathrm{C}\right) \\
\text { (B) }\end{array}$ & $\begin{array}{c}\text { Bar cross section }\left(\mathrm{mm}^{2}\right) \\
(\mathrm{C})\end{array}$ \\
\hline 1 & 5 & 665 & 64 \\
2 & 5 & 690 & 100 \\
3 & 5 & 715 & 144 \\
4 & 7 & 665 & 100 \\
5 & 7 & 690 & 144 \\
6 & 7 & 715 & 64 \\
7 & 9 & 665 & 144 \\
8 & 9 & 690 & 64 \\
9 & 9 & 715 & 100 \\
\hline
\end{tabular}

\subsubsection{Testing of Cast Samples}

After the casting of the bars, the cast produced were subjected to tensile test using a Monsanto tensometer (ASTM E8/E 8M -08 standard). Hardness test was conducted using Brinell hardness testing machine (ASTM E10-18 standard), while impact test was carried out using an impact testing machine (ASTE E23-07 standard).

\section{RESULTS AND DISCUSSION}

\subsection{Experimental results}

The results of the tensile, impact and hardness test for the bar along with their individual signal to noise $(\mathrm{S} / \mathrm{N})$ ratio value obtained using the criteria of 'larger is better' are shown in Table 7.

The main effect plot for the tensile strength, impact strength and hardness of investment casting bar when the mean of the signal to noise ratio at the three levels is plotted against the process factors (shell thickness, the pouring temperature and the bar cross section) are shown in Fig 7, 8 and 9 respectively, while Fig. 10 shows the combined effect of the process parameters on the mechanical properties
From Fig. 7, it can infer that the tensile strength is optimum when the shell thickness is at $5 \mathrm{~mm}$, the pouring temperature is at $665^{\circ} \mathrm{C}$ and the bar cross section is at $64 \mathrm{~mm}^{2}$. Also, Fig. 8 indicates that the impact strength is optimum when the shell thickness is at $5 \mathrm{~mm}$, the pouring temperature is at $665^{\circ} \mathrm{C}$ and the bar cross section is at $64 \mathrm{~mm}^{2}$ while Fig. 9 shows that the hardness is optimum when the shell thickness is at $5 \mathrm{~mm}$, the pouring temperature is at $665^{\circ} \mathrm{C}$ and the bar cross section is at $64 \mathrm{~mm}^{2}$. In addition, the main effect plots for tensile strength, impact strength and hardness shown in Fig. 7, 8 and 9 respectively showed a decreasing trend for the shell thickness. At thin shell thickness of $5 \mathrm{~mm}$, the conductive heat loss was high since the cooling rate increased, leading to faster rate of solidification, this caused an increase in the tensile strength, but as the shell thickness increased further, the rate at which heat was dissipated reduced because of the reduction in the conductive heat loss, which lead to the development of high thermal gradients which slowed the time of solidification, this caused the decrease in the mechanical properties observed in the decreasing trend in the tensile strength.

Table 7: Results of the tensile, impact and hardness test and the signal to noise ratio

\begin{tabular}{ccccccc}
\hline \multirow{2}{*}{ Run } & \multicolumn{2}{c}{ Tensile Strength $(\sigma)$} & \multicolumn{2}{c}{ Impact Strength $(\mathrm{Is})$} & \multicolumn{2}{c}{ Hardness $(\mathrm{H})$} \\
\cline { 2 - 7 } & $\sigma\left(\mathrm{N} / \mathrm{mm}^{2}\right)$ & $\mathrm{S} / \mathrm{N}$ ratio $(\mathrm{dB})$ & Is (joules) & $\mathrm{S} / \mathrm{N}$ ratio $(\mathrm{dB})$ & $\mathrm{H}(\mathrm{BHN})$ & $\mathrm{S} / \mathrm{N}$ ratio $(\mathrm{dB})$ \\
\hline 1 & 250.00 & 47.959 & 3.238 & 10.206 & 74.98 & 37.499 \\
2 & 234.01 & 47.385 & 1.910 & 5.621 & 74.70 & 37.466 \\
3 & 231.10 & 47.276 & 1.345 & 2.574 & 74.66 & 37.462 \\
4 & 230.05 & 47.236 & 1.712 & 4.670 & 74.65 & 37.461 \\
5 & 232.15 & 47.315 & 1.475 & 3.376 & 74.88 & 37.487 \\
6 & 235.20 & 47.429 & 1.356 & 2.645 & 74.72 & 37.469 \\
7 & 233.30 & 47.358 & 1.308 & 2.332 & 74.58 & 37.452 \\
8 & 220.25 & 46.858 & 1.287 & 2.192 & 74.63 & 37.458 \\
9 & 237.18 & 47.502 & 1.442 & 3.179 & 74.85 & 37.484 \\
\hline
\end{tabular}




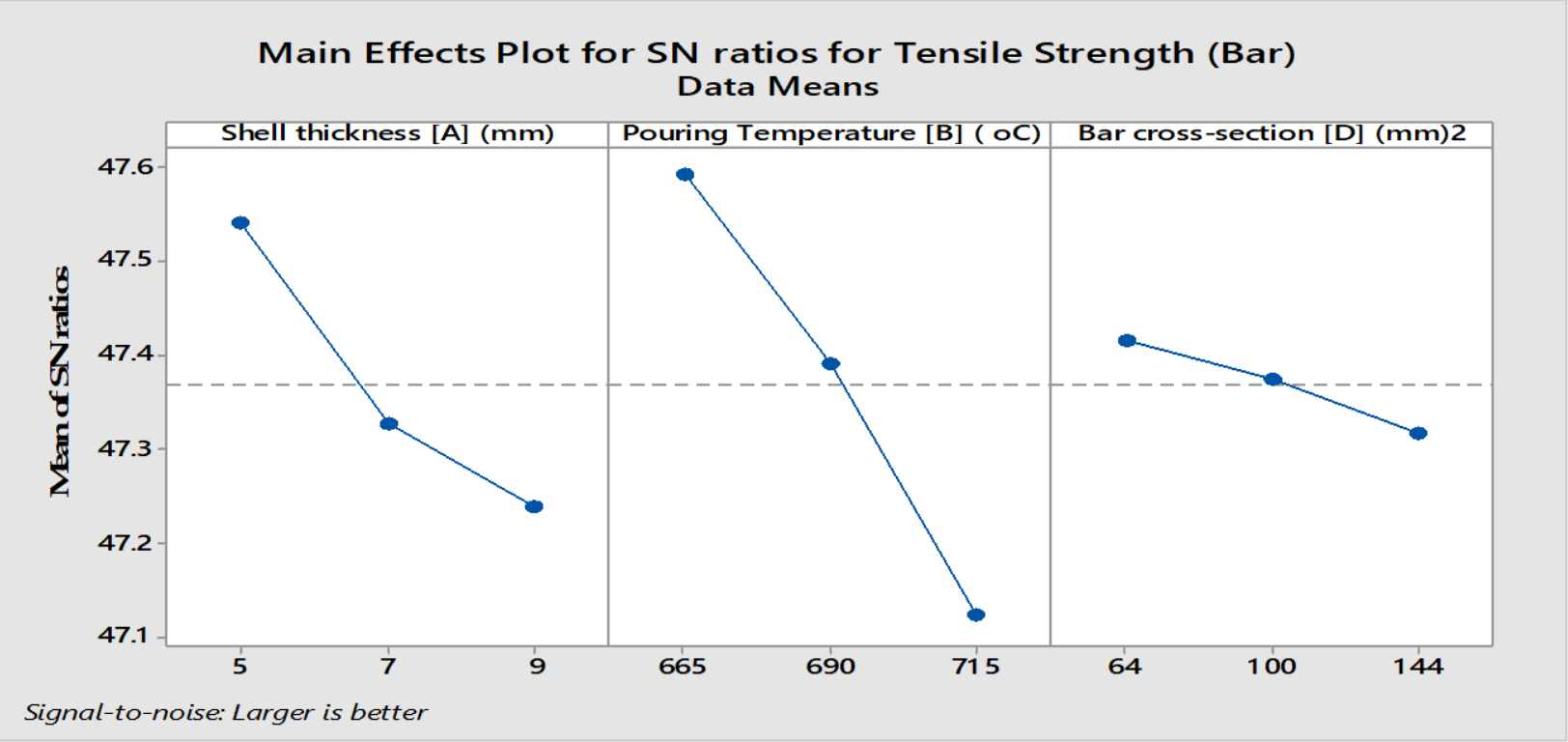

Fig. 7: Main effect plot for tensile strength

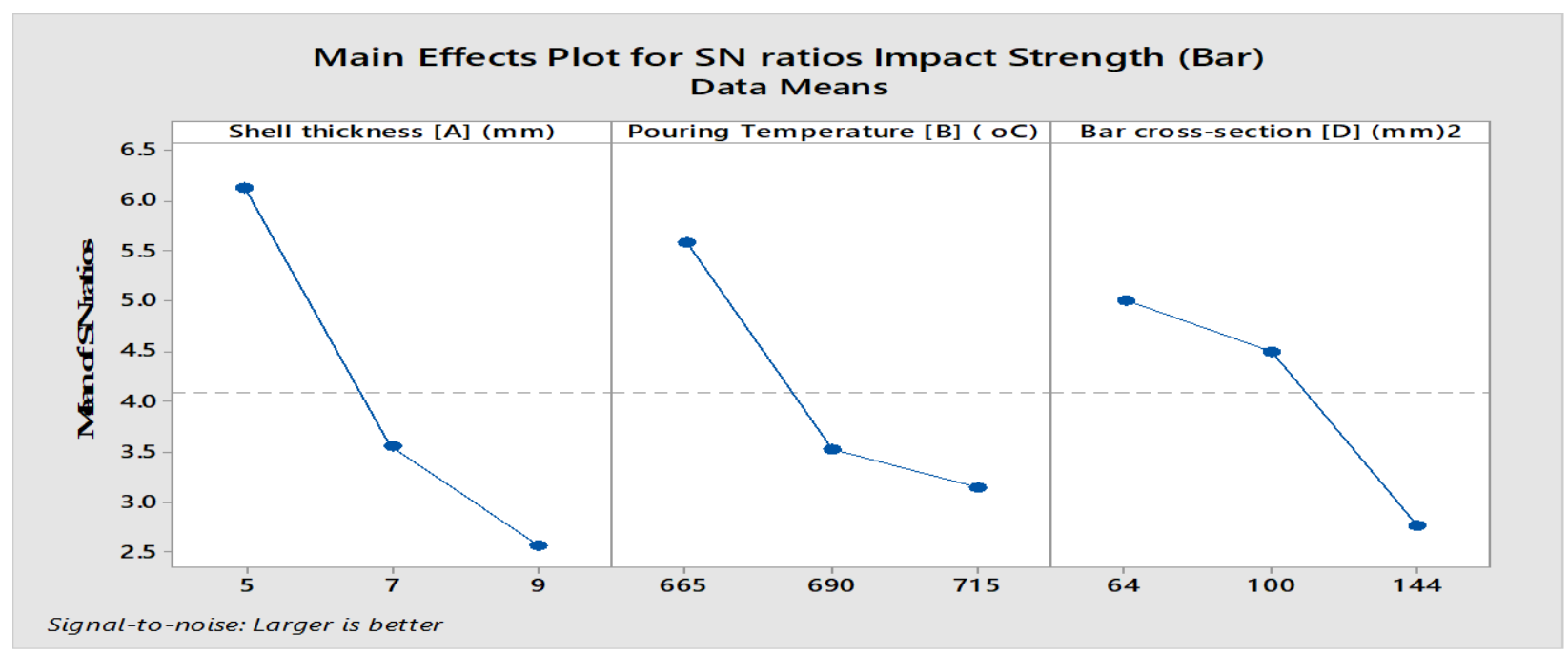

Fig. 8: Main effect plot for impact strength

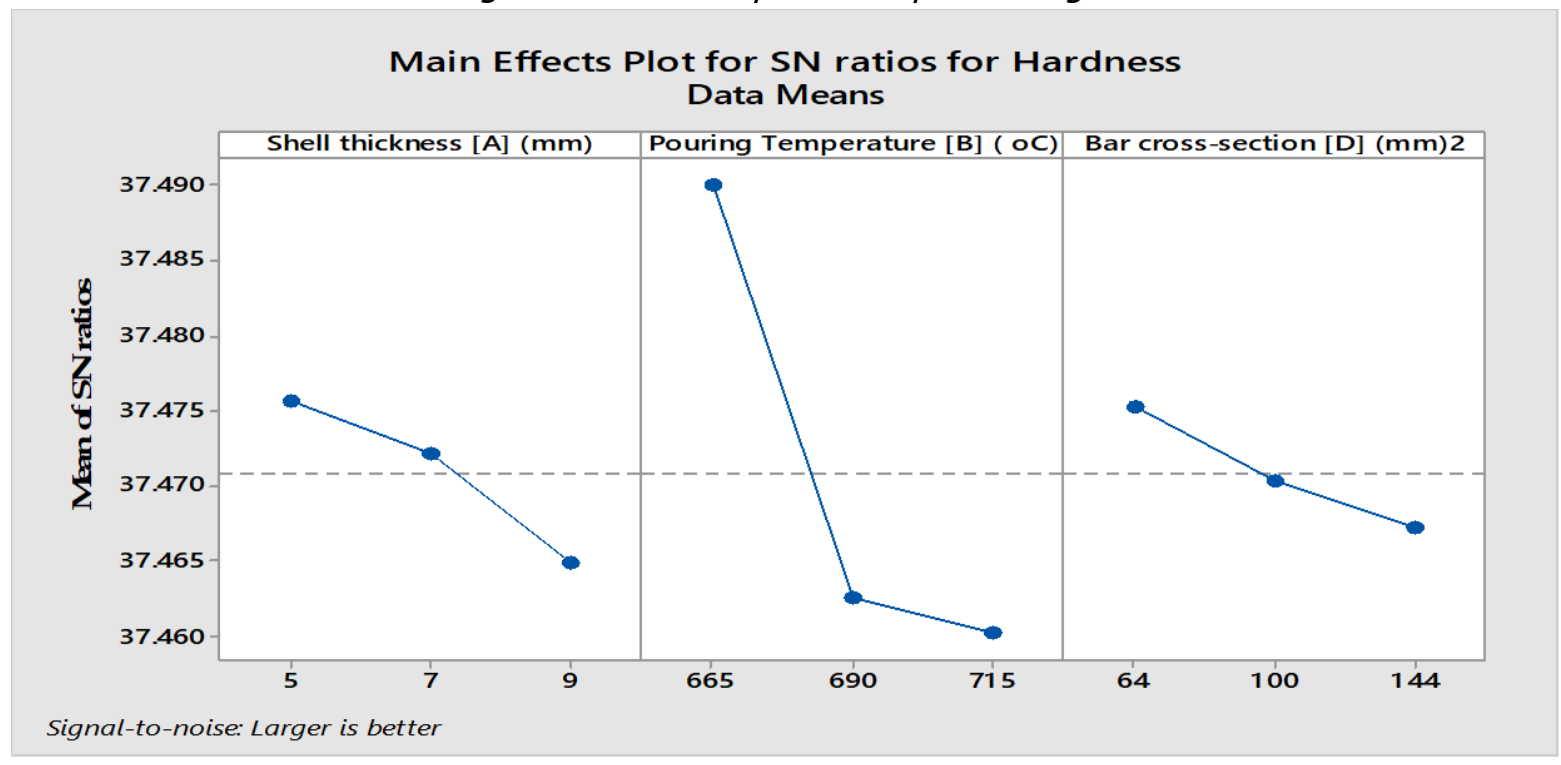

Fig. 9: Main effect plot for hardness 


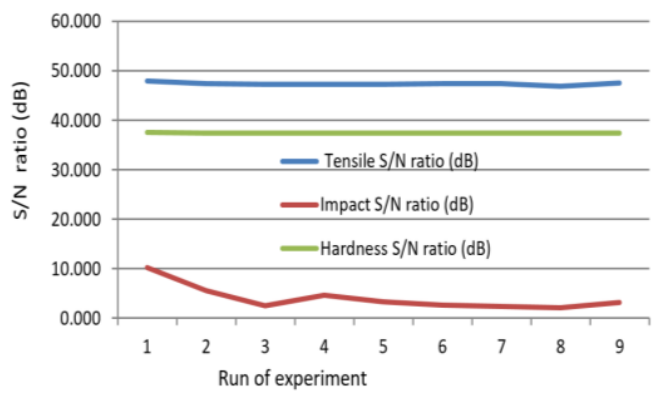

Fig. 10: Combined effect plot for the process parameters on the mechanical properties

There is a decreasing trend in all the mechanical properties as the pouring temperature increased, because the time for solidification to take place is increased due to the high thermal gradient and a slow cooling rate. This is similar to the earlier work of Nikhil and Karunakar [3], where it was concluded that higher pouring temperature significantly reduces the mechanical properties of investment cast aluminium alloy. Similarly, the Fig. 7, 8 and 9 also showed a decreasing trend in all the mechanical properties as the bar cross section was increasing, because as the bar cross section increases, the amount of molten metal increased, hence more heat is being dissipated at a slow cooling rate, thus slowing down the time required for solidification to take place. This decreasing trend was also observed in the work carried out by Sigworth [6], where some standard aluminium alloy test bars of varying thicknesses; 10, $12,22,36$ and $50 \mathrm{~mm}$ were used. It was observed that the tensile strength, impact strength and hardness decreased with the increasing thickness of the test bars. Also, Shrikant et a/[5], used step bars of varying thicknesses of 3,6, 10, and $16 \mathrm{~mm}$ and it was observed that as the bar thicknesses were increasing, the tensile and other mechanical properties were reducing. Fig. 10 shows the signal to noise ratios of the results obtained plotted against the run of experiments to illustrate the combined effect the process parameters have on the mechanical properties. From the plot, it was observed that the tensile strength and hardness are relatively stable within the average values of $47 \mathrm{~dB}$ and $37.4 \mathrm{~dB}$, which shows that the variation in the various process parameters does not have any significant combined effect on the tensile strength and hardness of the aluminium alloy (A356), however, it was observed that the impact strength was optimum at about 10.2 $\mathrm{dB}$ in the first run when the combined effect of the process parameters were thus: shell thickness at 5 $\mathrm{mm}$, the pouring temperature at $665^{\circ} \mathrm{C}$ and the bar cross section at $64 \mathrm{~mm}^{2}$ subsequently, the impact strength decreased in the second and third experiments as a result of the influence of the increasing pouring temperature, as observed in the works of Nikhil and Karunakar [3], in the fourth experiment, there was a slight increase in the impact strength to $4.67 \mathrm{~dB}$ because of the decrease in the pouring temperature, after which the combined effect of the process parameters were relatively maintained around $2.74 \mathrm{~dB}$ in the remaining experiments.

\subsection{Empirical model equations}

The empirical model equations for response variables (tensile strength, impact strength and hardness) along with their respective regression coefficient (Rsq) obtained using Minitab 17 software are shown in Equations 1, 2 and 3 . Where A represent the Shell thickness, $B$ is the Pouring temperature and $D$ is the bar cross sectional area.

$$
\begin{gathered}
\text { Tensile Strength }\left(\mathrm{N} / \mathrm{mm}^{2}\right)= \\
426.2-2.03 \mathrm{~A}-0.2529 \mathrm{~B}-0.0370 \mathrm{D} \\
\text { Rsq }=72.78 \% \text { and Rsq (adj) }=56.45 \%
\end{gathered}
$$

Impact Strength (joules) $=$

$$
12.19-0.2047 \mathrm{~A}-0.01207 \mathrm{~B}-0.00730 \mathrm{D}
$$

Rsq $=66.82 \%$ and $\operatorname{Rsq}(\operatorname{adj})=46.92 \%$

Hardness $(\mathrm{BHN})=$

$$
\begin{aligned}
& 78.533-0.0233 A-0.00513 B-0.000865 D \\
& \text { Rsq }=83.00 \% \text { and Rsq (adj) }=72.80 \%
\end{aligned}
$$

When the optimized parameters obtained from the main effect plot were substituted in the empirical model equations the following optimal values were obtained:

Tensile Strength $\left(\mathrm{N} / \mathrm{mm}^{2}\right)=245.50 \mathrm{~N} / \mathrm{mm}^{2}$. Impact Strength (joules) $=2.673$ joules .

Hardness $(\mathrm{BHN})=74.95 \mathrm{BHN}$.

In addition, when confirmatory test was conducted to validate the values of the optimal parameters for the bar the following results shown in Table 8 were obtained.

From the computed values of the optimized parameters and the confirmatory test, it is clear that Equations 1, 2 and 3 are valid within the limits of the experimental conditions being conducted. 
Table 8: Results of confirmatory test

\begin{tabular}{lccc}
\hline Response & Experimental value & Calculated value & Percentage error \\
\hline Tensile Strength N/mm & 242.10 & 245.50 & $1.38 \%$ \\
Impact Strength (joules) & 2.655 & 2.673 & $0.67 \%$ \\
Hardness (BHN) & 74.60 & 74.95 & $0.47 \%$ \\
\hline
\end{tabular}

\section{CONCLUSIONS}

From the results obtained the following conclusions are drawn:

i. Investment slurry composition by weight of $30 \%$ PoP, $20 \%$ silica sand and $50 \%$ water were the most suitable used to produce the investment shells.

ii. Shells of $5 \mathrm{~mm}, 7 \mathrm{~mm}$ and $9 \mathrm{~mm}$ were produced from the investment slurry and $5 \mathrm{~mm}$ shell was found to be the most suitable.

iii. Optimisation carried out reveal that tensile strength, impact strength and hardness were optimum in the bars when the shell thickness was $5 \mathrm{~mm}$, pouring temperature was $665^{\circ} \mathrm{C}$ and bar cross section was $64 \mathrm{~mm}^{2}$.

Therefore, it can be recommended that Aluminium silicates (mullite) which is also readily available be incorporated in the investment slurry instead of silica sand and the properties of castings could be compared with those of the present investigation.

\section{REFERENCES}

[1]. Wu, S., Xie, L., Zhao, J. Nakae, H. (2008). Formation of non-dendritic microstructure of semi-solid aluminium alloy under vibration. Scripta Materialia 58(7), 556-559, doi: 10.1016/j.scriptamat.2007.11.010
[2]. Legoretta, E.C., Atkinson, H.V., and Jones, H. (2008). Cooling slope casting to obtain thixotropic feedstock II: observations with A356 alloy. Journal of Material Science 43:5456. Retrieved from https://link.springer.com. Retrieval date- July 29, 2017.

[3]. Nikhil,Y., \& Karunakar, D.B. (2011). Effect of process parameters on mechanical properties of investment casting. International journal of Advances in Engineering and Technology. 1(3), 128-137

[4]. Phuan, Y.J., (2005). Evaluation of Thermal Property of Mould Wall Material for Investment Casting and the Effect of Layers on the Hardness of the Cast Product. B.Eng Thesis, Mechanical Engineering, University of Technology, Malaysia.

[5]. Shrikant, S., Bhat, M.N., Kumar, A., Pratik, A., Amitesh, K. (2014). Effect of section thickness on the microstructure and hardness of gray cast iron (a simulation study). International Journal of Engineering Research and Technology. 3(7). Retrieved from http://www.ijert.org Retrieved on August 4, 2017.

[6]. Sigworth, G.K., (2011). Understanding Quality in Aluminium castings. International Journal of Metalcasting 5 (1), 7-22. 